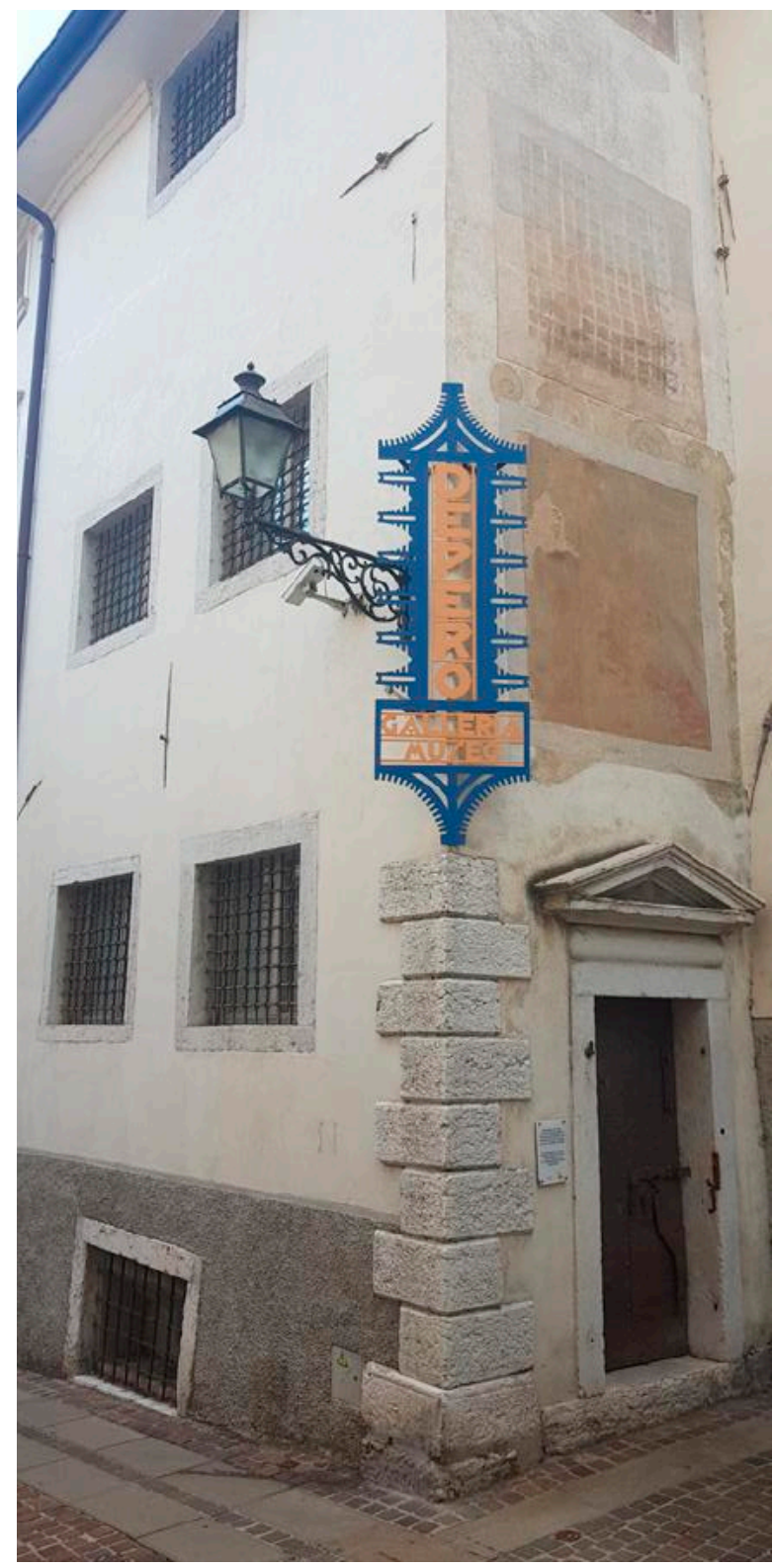

Antigua entrada de la Galería Museo Depero por via della Terra 53 (1959-1991).

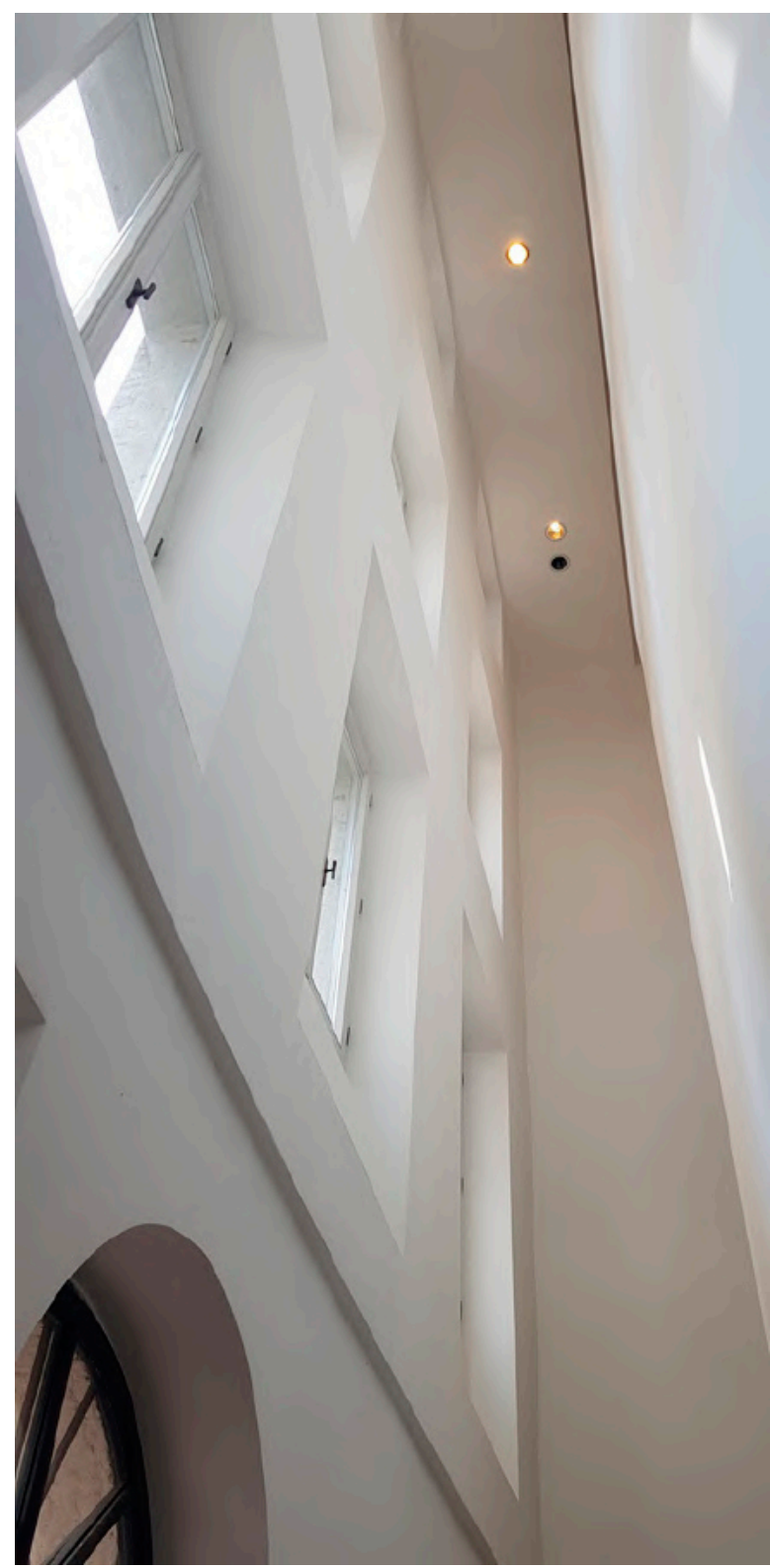

Casa d'Arte Futurista Depero. Restauración de Renato Rizzi (2009). 


\section{LA CASA DEL MAGO. EL MUSEO FUTURISTA \\ DE FORTUNATO DEPERO EN ROVERETO'}

\section{THE HOUSE OF MAGO. THE FUTURISTIC MUSEUM OF FORTUNATO DEPERO IN ROVERETO}

Palabras clave

Abstract

Keywords
Juan Agustín Mancebo Roca Universidad de Castilla-La Mancha

Resumen

A principios de los cuarenta del pasado siglo Fortunato Depero concibió la idea de un museo sobre su obra y tras un periodo en el que sus vínculos políticos ensombrecieron su trabajo, proyectó en la década siguiente su Galería Museo en Rovereto. Artista esencial del futurismo, vanguardia que había abogado programáticamente por la destrucción de museos y academias, Depero creó un espacio que resumía su legado constituyendo la base de lo que hoy es el Museo de Arte Moderna e Contemporanea de Trento e Rovereto. Este artículo hace un recorrido por el itinerario artístico de Fortunato Depero, sus vínculos con el futurismo y con su ciudad de adopción, así como por la evolución de la Casa d'Arte Futurista como modelo para la Galería Museo. Asimismo, se referencia la colección permanente según el proyecto del artista y las exposiciones temporales que toman como base los fondos del Archivio del' 900 que reivindican la reconstrucción de la memoria del siglo xx. El artículo concluye que la Casa d'Arte Futurista Depero ha dinamizado el contexto cultural trentino configurando su proyecto museográfico actual.

Artes aplicadas, diseño, futurismo, fascismo, museo, Mart, Rovereto.

In the early forties of the last century, Fortunato Depero conceived the idea of a museum about his work. After a period where his political ties overshadowed his artistic legacy, he projected his Gallery Museum in Rovereto in the following decade. An essential artist of Futurism, an avant-garde that had programmatically advocated the destruction of museums and academies, Depero created a space that summed up his legacy and formed the basis of what it is today the Museo d'Arte Moderna e Contemporanea di Trento e Rovereto. This article traces the artistic itinerary of Fortunato Depero, his links with Futurism and his adopted city, as well as the evolution of the Casa d'Arte Futurista as a model for the Museum Gallery. Reference is also made to the permanent collection according to the artist's project and to the temporary exhibitions based on the archives of the Archivio $\operatorname{del}^{\prime} 900$, which claim the reconstruction of the memory of the twentieth century. The article concludes that the Casa d'Arte Futurista Depero has dynamized the cultural context of Trentino by shaping its current museographic project.

Applied Arts, Design, Futurism, Fascism, Museum, Mart, Rovereto

1 Este artículo ha sido escrito mediante el Programa de estancias en universidades y centros de investigación en el extranjero 2021 del Plan Propio de Investigación de la UCLM y el Fondo Europeo de Desarrollo Regional (FEDER). El autor agradece a Paola Pettenella, Duccio Dogheria, Patrizia Regorda y especialmente a Federico Zanoner del Archivio del' 900 así como a Mariarosa Mariech (responsable de la biblioteca) y al profesor Denis Viva del Dipartimento di Lettere e Filosofia dell'Università degli Studi di Trento su generosa ayuda para su elaboración. 


\section{Introducción}

Queremos destruir los museos, las bibliotecas, las academias de todo tipo y combatir el moralismo, el feminismo y todas las cobardías oportunistas y utilitarias.

Filippo Tommaso Marinetti, 20 de febrero 1909

Desde su inauguración en 1959 y su reapertura tras la restauración de 2009, la Casa d'Arte Futurista Depero se publicita como el único museo futurista de Italia. Hay otros espacios dedicados al movimiento como la Fondazione e Museo Primo Conti en Fiesole ${ }^{2}$ y la Casa Balla en Roma ${ }^{3}$, además de archivos personales como los de Gerardo Dottori, Cesare Andreoni, Franco Casavola, Corrado Govoni, Arnoldo Bonzagni, Balilla Pratella, Gian Piero Lucini y Mario Chiattone entre otros (Giroud y Pettenella, 2003: 77- 267). Lo que diferencia la Casa Depero del resto es que fue el propio artista quien proyectó el museo durante años a través de un sistemático fondo en el que catalogó su trabajo y sus referencias constituyendo un prodigioso archivo a partir de la relectura del auto-rèclame futurista (Depero, 2012: 104). Entre sus miles de documentos el archivo Depero contiene el Dizionario ideologico ed autobiografico compuesto por seis volúmenes y trece cuadernos que abarca su recorrido biográfico y artístico desde 1904 hasta los años

2 Creada en 1980 la Fondazione e Museo Primo Conti a partir del legado de Primo Conti (1900-1988) acoge una muestra permanente sobre su obra y fondos documentales de vanguardia. Contiene entre otros los Archivi Giovanni Papini (1980) y Primo Conti (1985), los fondos Librario Futurista (1980-87), Franceso Meriano (1981), Francesco Cangiullo (1981), Emilio Settimelli (1985), Francesco Balilla Pratella (1985), Corrado Pavolini (1985), Emilio Notte (1990), Giuseppe Bottai (1995), Osvaldo Peruzzi (1998) y los del historiador Mario Verdone (1987).

3 La Casa Balla en el barrio de Prati en via Oslavia 39B ha sido recientemente restaurada y abierta al público a partir de la intervención del Maxxi Roma. La de Oslavia fue la última de las sedes de la homónima casa futurista. La casa se puede visitar los fines de semana del 26 de mayo al 24 de octubre de 2021 y su apertura se complementa con una exposición en el Maxxi, Casa Balla. Dalla casa all'universo e ritorno (17 junio21 noviembre de 2021). cincuenta realizado «con la idea de publicar una obra enciclopédica que fuese una especie de compendio de su credo artístico y de sus experiencias de vida» (Velardita, 2008: 63-64).

Fortunato Depero fue uno de los escasos miembros del futurismo que se mantuvo fiel al movimiento desde su adscripción hasta el final del grupo en diciembre de 1944. El artista siguió considerándose un pintor futurista más allá del sinsentido de una filiación que remitía a un mundo que había desaparecido. De hecho, el catálogo y la exposición inaugural de la Galleria e Museo Depero Rovereto en 1959 se iniciaban con su carta de admisión dirigida a Giacomo Balla por la dirección del grupo futurista (Mart, Dep. 1.1.3) «que subraya una carrera artística coronada por la construcción del citado museo» (Zanoner, 2021: 7).

La Casa d'Arte Futurista Depero es una de las escasas referencias museísticas futuristas, un movimiento de vanguardia que ha estado y probablemente sigue estando bajo sospecha y cuya implicación con el fascismo ha condicionado gran parte de su lectura historiográfica ${ }^{4}$. Del mismo modo, la Casa d'Arte Depero está inextricablemente ligada al contexto cultural de Rovereto ya que constituyó el germen de la política museística contemporánea del Trentino a partir de la fundación del Mart, el Museo di Arte Moderna e Contemporanea di Trento e Rovereto en 1987, que aunaba las colecciones del siglo XIX organizadas por la historiadora del arte Gabriella Belli (1952-) en el Palazzo delle Albere de Trento y los fondos documentales y artísticos de la Casa Depero de Rovereto, configurando un ambicioso proyecto más allá de una lectura provincial con vocación, como así ha sido, de trascender internacionalmente.

Este artículo estudia la Casa d'Arte Futurista Depero desde sus orígenes hasta la actualidad como una de las tres sedes del Mart. Para ello se estructura un recorrido histórico-artístico sobre

4 «El futurismo ha salido definitivamente del armario, varias exposiciones lo celebran y sus artistas se revalorizan en el mercado [...] la mejor expresión de la dicotomía moral entre el arte de vanguardia y la política de su tiempo» (Verdú, 2021). 


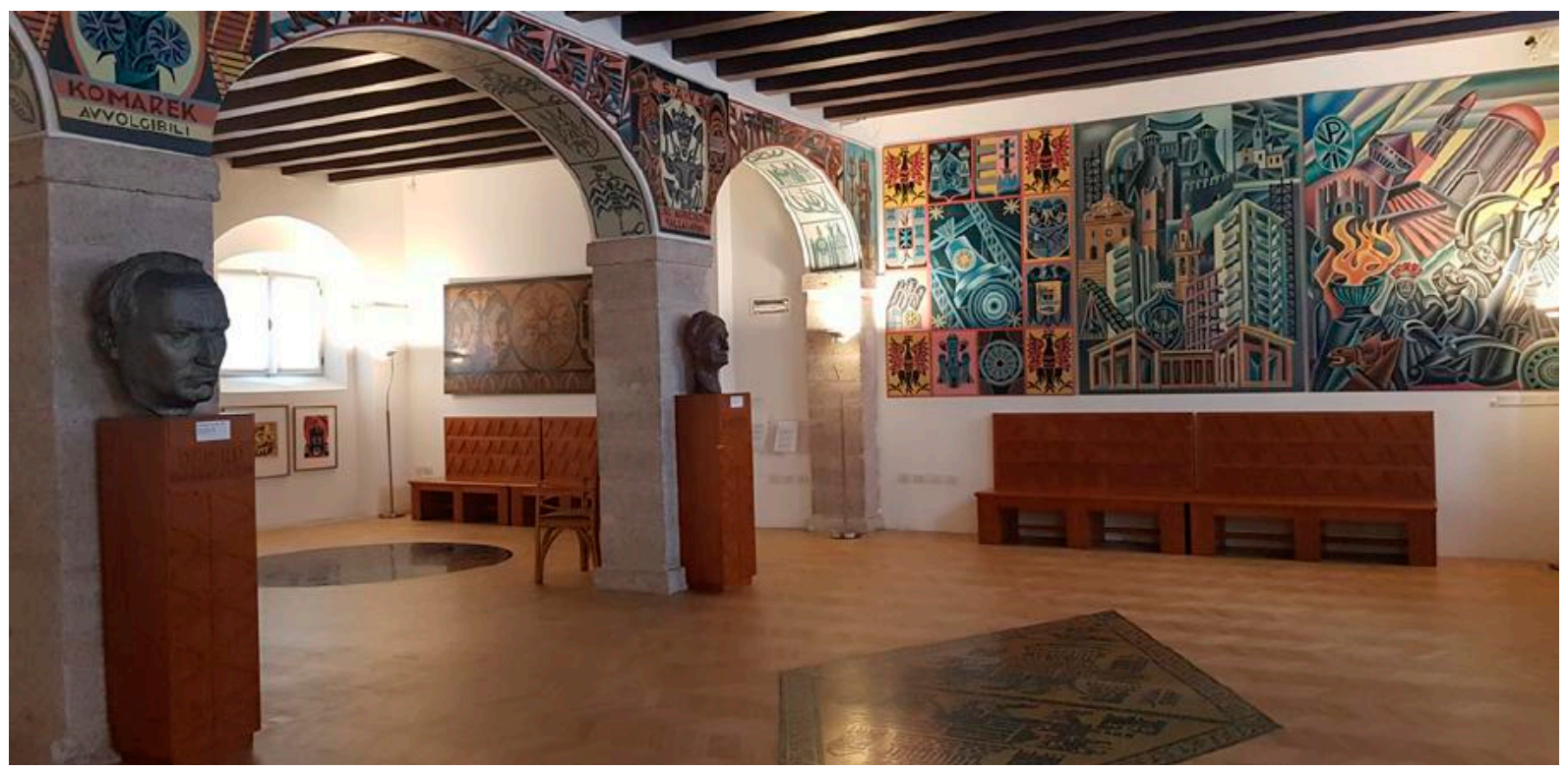

Sala Rovereto. Al fondo los cuadros Pietre antiche e moderne, Vampa Eroica, Generosità sconfinata (1957-1959). En primer plano los retratos de Fortunato Depero y Rosetta Amadori realizados por Eraldo Fozzer.

la filiación futurista de Depero y su relación con Rovereto. Asimismo, el trabajo se focaliza en la concepción de la Galeria Museo Depero, las diferentes propuestas para constituirla, su particular historia -ya que fue cerrada tras su inauguración solo accesible a los gestores e historiadores para consulta de los fondos-, su ampliación, la colección permanente y las muestras temporales.

A partir del renovado interés en la obra de Depero y del futurismo italiano, se reabrió el museo en temporada estival, previamente a su apertura durante todo el año. A este respecto fueron determinantes los fondos documentales que constituyeron el germen del actual Archivio del'900. El artículo concluye con el impulso que se le ha dado a la Casa d'Arte Futurista Depero a principios del siglo XxI con la restauración de 2009 en el que el museo se ordena como parte esencial del Polo Culturale Museale de Rovereto ${ }^{5}$, un espacio dedicado a la obra de

5 «El nuevo Polo Culturale Museale di Rovereto está situado en Corso Bettini a la altura de los dos Palacios Alberti y Annona. Comprende el MART, la ampliación de la Biblioteca Civica, un Auditorium y un edificio para actividades expositivas culturales del Ayuntamiento» (Cerone, 2003: 109). un artista y a una vanguardia cuya programática pretendía la aniquilación de todos ellos.

\section{Depero futurista}

Fortunato Depero nació en 1892 en Fondo, un pequeño pueblo en el Val di Non en los confines del Trentino administrado por el imperio austrohúngaro. En 1902 su familia se trasladó a Rovereto y, tras su formación en la Scuola Reale Elisabettina, se presentaría sin éxito a los exámenes de la Academia de Arte de Viena (1909). Tras ese fracaso, su padre firmó un contrato el 21 de noviembre de 1910 para que el joven artista aprendiera el oficio de marmolista en la empresa de Gelsomino Scanagatta (Mart, Dep. 1.1.1).

Su carácter inquietó y la disconformidad con el ambiente artístico de Rovereto -en ese momento era asiduo lector de «Lacerba» revista futurista dirigida por Giovanni Papini (1881-1956) y Ardengo Soffici (1879-1964)le llevaron a mudarse a Roma en 1913 donde entraría en contacto con la Galería Futurista Permanente de Giuseppe Sprovieri (18901988). En la capital frecuentaría el estudio de 


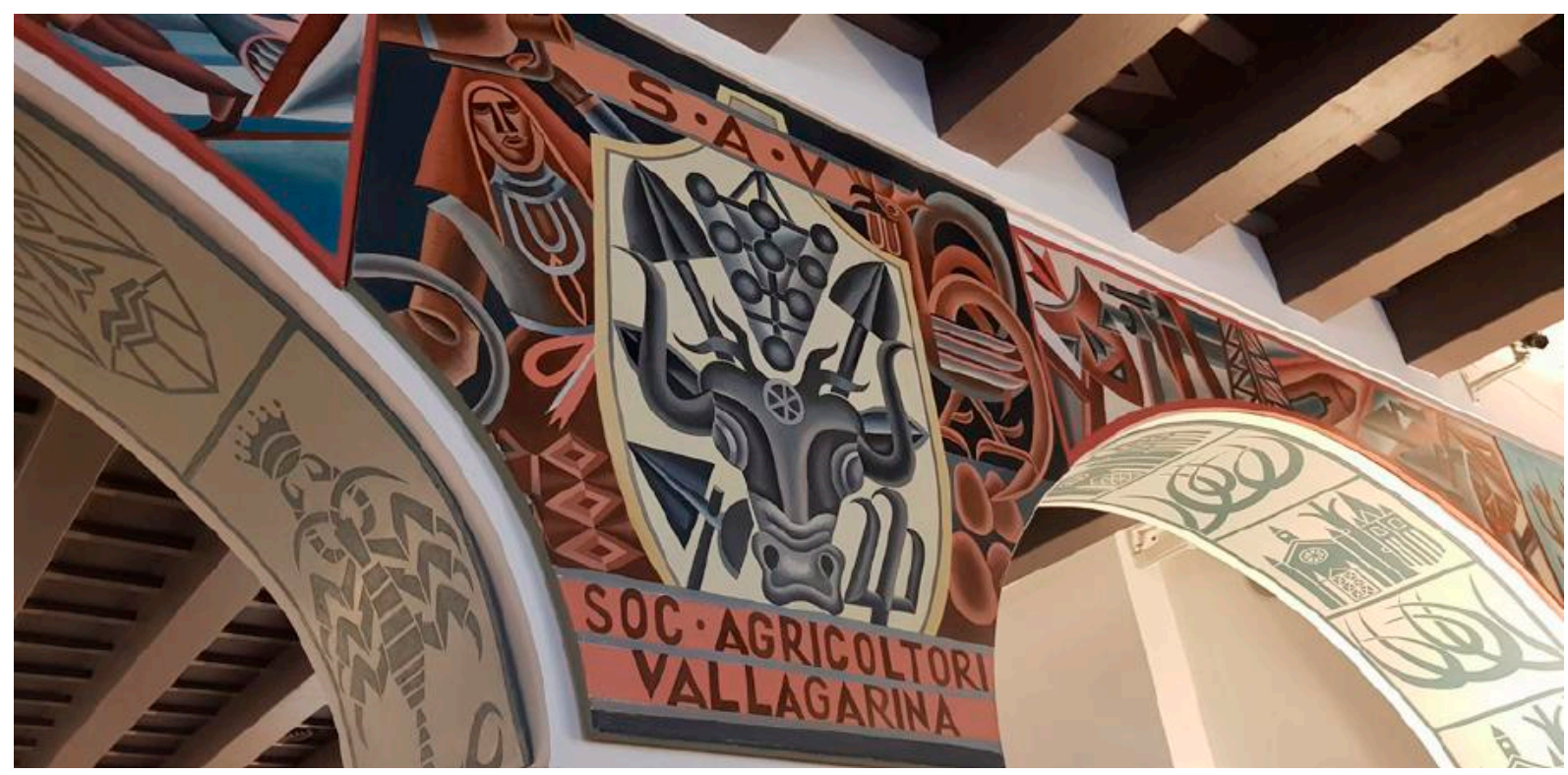

Sala Rovereto: Società Agricoltori Vallagarina (1957-1959).

Giacomo Balla (1871-1956) otrora maestro de Gino Severini (1883-1966) y Umberto Boccioni (1882-1916). La sintonía artística entre Balla y Depero fue instantánea y este pasaría a ser su más estrecho colaborador. Por otra parte, Depero se sintió fascinado por la obra de Boccioni que conoció en la Galeria Sprovieri (Depero, 2012: 11-12). A partir de la lectura de la obra de Boccioni y de los trabajos previos de Balla, ambos investigarían la posibilidad de incorporar el movimiento y el ruido a la obra de arte generando los complessi plastici, esculturas dinámicas realizadas con materiales pobres que constituyeron el primer paso para superar la jerarquía de los géneros artísticos tradicionales. Depero se convirtió en futurista en 1914 aunque su membresía bien pudiera ser algo posterior y hacerse efectiva en 1915 ya que como movimiento dogmático y jerarquizado los futuristas intervenían premeditadamente en la datación de las obras y en las biografías de sus miembros para construir un relato que se adecuara coherentemente a sus fines propagandísticos.

En cualquier caso, Depero había expuesto siete obras en la Esposizione Libera Futurista
Internazionale (1914) y publicaría con Balla Ricostruzione futurista dell'universo (Milán, 11 de marzo de 1915) que se alejaba de la retórica anti-pasadista para configurar un modelo que pretendía eliminar las barreras entre las disciplinas artísticas y la división entre arte y vida. El texto proponía una pauta de construcción de totalidad orgánica a partir de la renovada visión de la vanguardia y condicionaría la segunda parte de esta hasta los años treinta lo que suponía «la codificación de la programática totalidad operativa de la creatividad futurista» (Crispolti, 2015: 13).

La intervención futurista llevó a la reelaboración de la idea de la obra de arte total, la gesamtkunstwerk wagneriana que el movimiento tradujo en la creación de las diferentes Case d'Arte Futuriste, «laboratorios experimentales de un trabajo dirigido a replantear el espacio cotidiano, de los objetos de uso a la decoración de la casa, de la moda a la escena urbana» (Giacomelli, 2001: 232). Pese a que se distribuirían por toda Italia -como las de Pippo Rizzo (1897-1964) en Palermo (1921-1929) o la de Tato (Guglielmo Sansoni 1896-1974) en Bolonia (transferida a la capital un año des- 
pués)-, Roma se convertiría en su epicentro y con ellas en la capital del movimiento (Bossaglia, 1993: 9). Las más relevantes fueron la Casa d'Arte Bragaglia (1918-1930) de Anton Giulio Bragaglia (1890-1960) que se convertiría en un espacio escénico de referencia con el Teatro degli Independienti «el primero y más importante intento de renovación del arte teatral italiano en las primeras décadas del novecientos» (Mondello, 1990: 31); la Casa d'Arte Italiana (1919-1921) del crítico Mario Recchi y de Enrico Prampolini (1894-1956) completamente diseñada por este y la Casa d'Arte Balla (1920-1958) cuya sede estuvo primero en la via Niccolò Porpora 2 y finalmente en via Oslavia 39B, donde se ubica actualmente, a las que habría que unir los talleres de menor entidad de Ugo Giannattasio (1888-1958) entre 1920 y 1923 dedicado a la cerámica, la decoración y el mobiliario y la de Roberto Melli (1885-1958).

\section{Rovereto-París-Nueva York-Rovereto}

Tras cinco años en Roma, Depero volvió a Rovereto y en otoño de 1919 puso en marcha los talleres de la Casa d'Arte Depero en los que debía concretar los preceptos de Ricostruzione futurista dell'universo en una ciudad castigada por la guerra -severamente bombardeada por la artillería italiana- y alejada de los núcleos artísticos de Milán, Roma y Florencia.

La noticia de la apertura se había publicado el 5 de junio en las "Cronache d'Attualità» de Bragaglia: «El pintor Depero fundará un gran establecimiento para muebles y objetos de artes decorativas en el Trentino» (Belli, 1992: 20). Si bien es cierto que la Casa de Depero fue algo posterior al resto de casas de arte y estaba basada en las iniciativas futuristas señaladas, lo cierto es que se distinguió por un ambicioso programa determinado por la producción de elementos en tela. Depero junto a su mujer Rosetta Amadori (1893-1976) había iniciado sus primeras experiencias sobre manufactura de

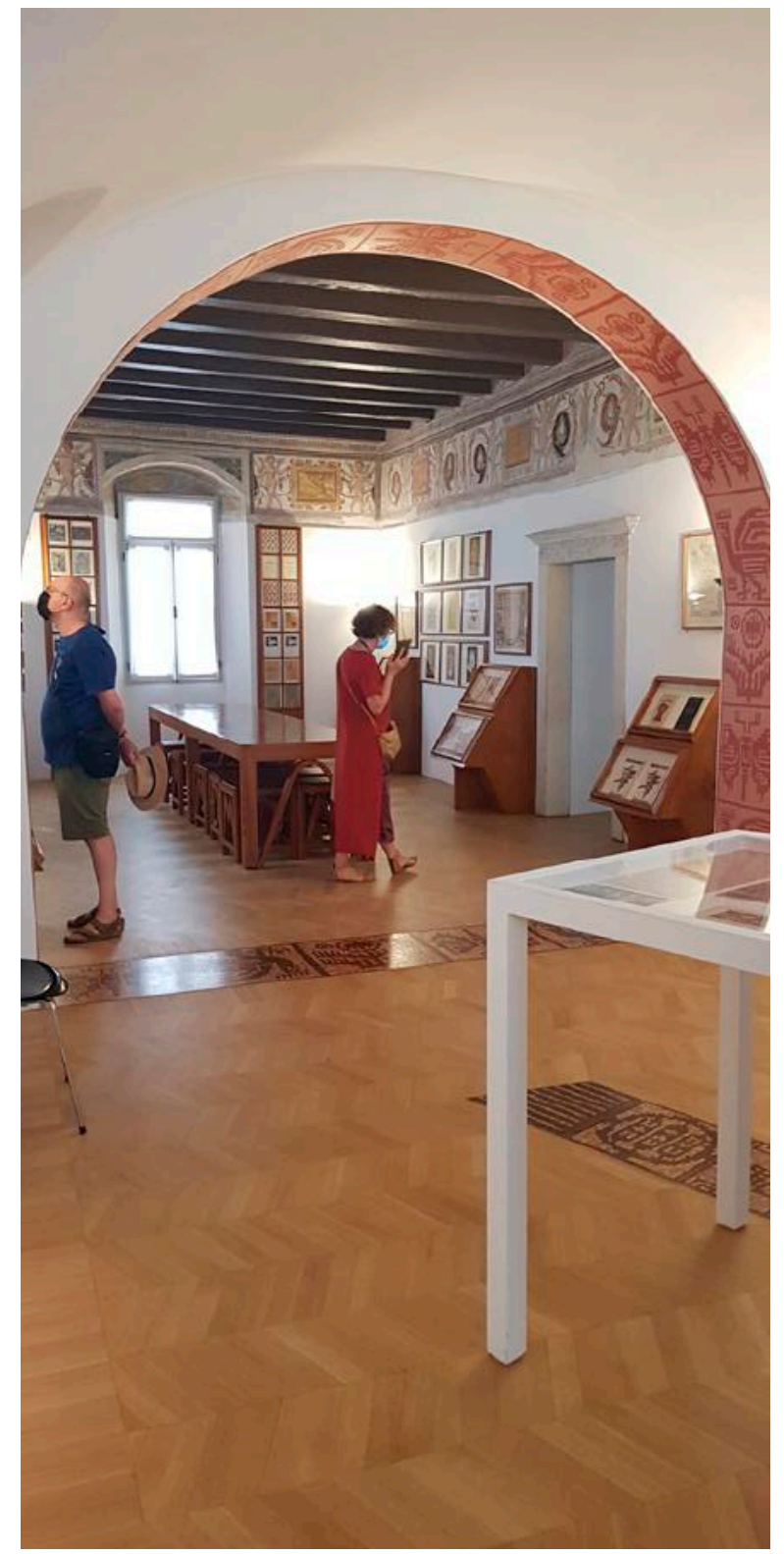

Sala «eco della stampa» realizada por Fortunato Depero (1957-1959).

tejidos durante la estancia en Capri con Gilbert Clavel (1883-1927) a partir de los remanentes de «tela española» del frustrado proyecto del Le chant du rossignol (1917) para Ballets rusos de Serguéi Diághilev (1872-1929).

La primera sede de la Casa d'Arte Depero estuvo en un pequeño local de apenas unos metros cuadrados en la via Vicenza en el que trabajaban el artista y su mujer -determinante en la intendencia y el buen funcionamiento de 


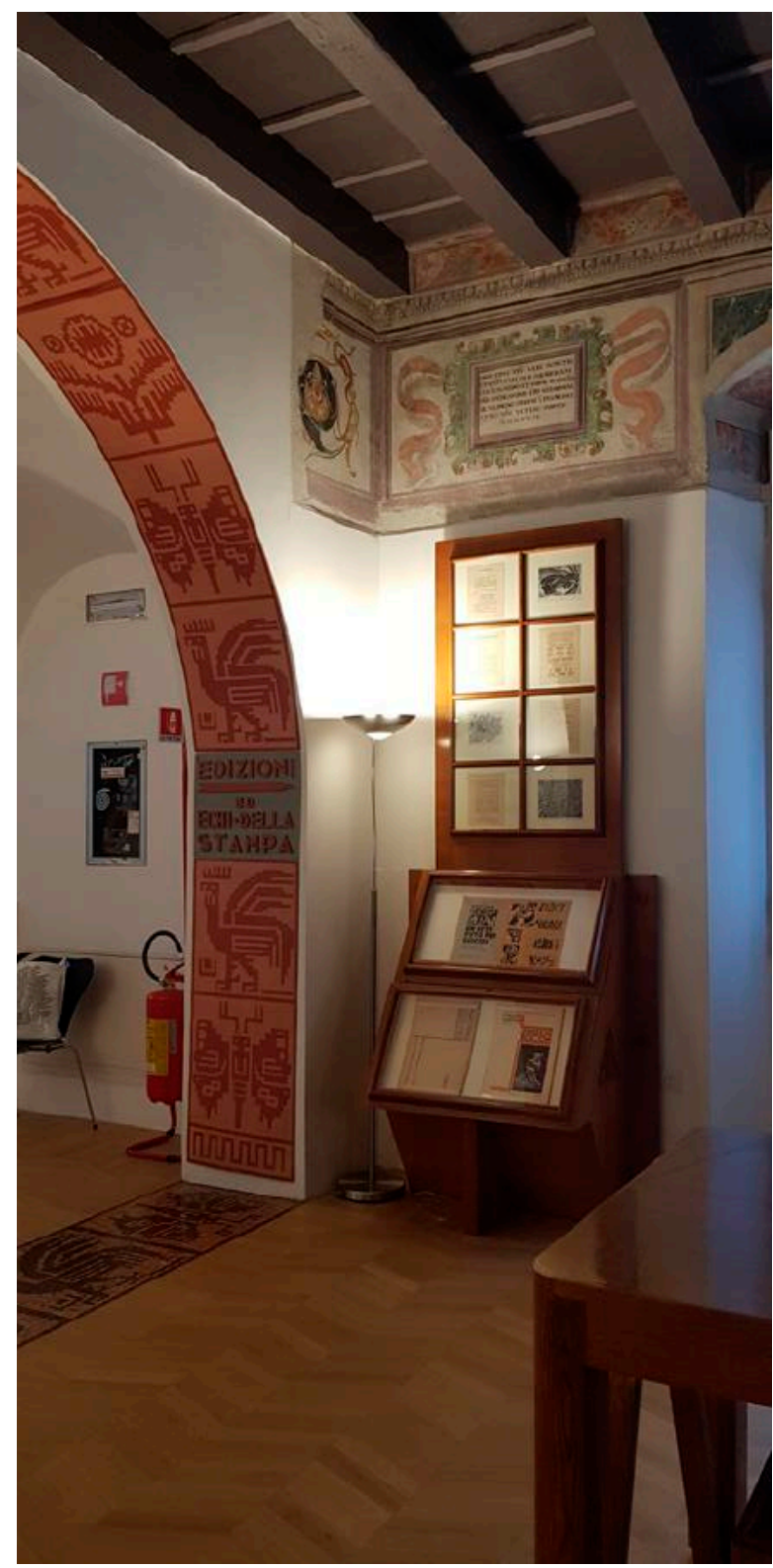

Sala «eco della stampa». En la parte superior pinturas originales de la casa de Monte dei Pegni.

la Casa- que se encargaba con un operario de confeccionar los tapices diseñados por el artista. La falta de espacio motivó su traslado en agosto de 1920 a los salones de la casa Keppel en via 2 Novembre, 14 -actualmente via Santa Maria 44-donde incrementó exponencialmente su producción. Con una clara vocación publicitaria, sus productos fueron expuestos en la milanesa galería Moretti en el Palazzo Cova desde el 29 de enero al 20 de febrero y en la Casa d'Arte Bragaglia entre el 15 de marzo y el 15 de abril de 1921 que atestiguaban la frenética producción diferenciada en varios sectores de la Casa d'Arte Depero.

La Casa en un principio fue ideada para realizar tapices de grandes dimensiones que derivarían en artes decorativas, mobiliario y juguetes y cuya originalidad fue reconocida con una mención en la Exposition Internationale des Arts Décoratifs de París (1925) en la que Depero presentaría sus trabajos con Balla y Prampolini como atestigua la conocida fotografía con Guglielmo Jannelli (1895-1950) y Balla portando los primeros los célebres panciotti-chalecos-futuristas (Mart, Dep. 2.6.63).

Pese a estar focalizado en la producción de elementos artesanales, Depero nunca abandonó la pintura ya que las ventas de objetos le permitieron dedicarse a ella con cierto desahogo (Scudiero, 1992: 6). Un buen ejemplo sería La casa del Mago (1920) en el que aparece pintando mientras los operarios trabajan en los tapices y cuyo estilo evolucionaba del futurismo a una particular lectura solar de la metafísica.

El reconocimiento de la Casa d'Arte Depero en las exposiciones internacionales le llevaron a contratar más trabajadores para acelerar una producción que por su especificidad era muy laboriosa. Con la idea de diversificar las sedes y hacerse más accesible pensó en transferir la Casa d'Arte a Milán, proyecto que tuvo en mente hasta 1927, cuando contempló la internacionalización de su trabajo en Estados Unidos y canceló el traslado a Lombardía. Con una proyección similar, a raíz de la citada Exposition Internationale des Arts Décoratifs, Depero abrió la Maison Depero en la parisina rue Sansovere 93 que cerraría en primavera de 1926 por la falta de proyectos y encargos (Belli, 1992: 30).

Fascinado por las imágenes de Nueva York que habían configurado las utópicas visiones arquitectónicas de Antonio Sant'Elia (1888- 
1916) y Mario Chiattone (1891-1957) y con la esperanza de encontrar un mercado para su trabajo, Depero iniciaría su aventura americana que había proyectado durante más de un año. Pese a que Marinetti se lo había desaconsejado y Fedele Azari le había señalado las dificultades que había tenido en Estados Unidos $^{6}$, el matrimonio Depero y su monumental equipaje partieron a bordo del Augustus desde Génova el 28 de septiembre de $1928^{7}$.

Pese a que fue arropado por la comunidad italiana, Depero se topó con todo tipo de trabas burocráticas además de la falta de una base financiera que le permitiera desarrollar su programa. Puso en marcha la New York Depero's Futurist House, una Casa d'Arte subsidiaria de la sede roveretana en una habitación alquilada a su colega de infancia Ciro Lucchi y a su socio Albert Jackson de la New Transit Import \& Export Co., en el 464 West 23rd de la calle 25. Convencido del éxito, Depero firmaría un contrato societario de dos años por el que les cedería parte de los beneficios, pero la sociedad fue disuelta el 1 de abril por falta

6 «Resumiendo, ¡aquí hay muchas dificultades y muy distintas de los que pensaba! [...] Te podré dar una idea exacta de este ambiente, que no me gusta y que está muy lejos de nuestras tendencias y posibilidades... pero sin embargo me tienta [...] y si tuviera que volver aquí para cualquier empresa sería contigo. Porque el único camino posible es la industrialización del arte» (Azari, 1992: 23).

7 «Cargo un camión lleno y me sitúo entre las pilas de cuadros, sujetando los cuadros de arriba abajo con las piernas y los brazos extendidos, para que no se derrumben o se estropeen durante el duro transporte. Mis sueños mágicos, mi mundo de cuento de hadas, los autómatas mecánicos, los trenes voladores, la flora y la fauna mágicas, viajan entre los muros de plomo de los rascacielos, entre las perspectivas de hierro de los puentes y los trenes elevados, siguiendo la corriente compacta de los coches, entre dos bancos de multitudes negras que pululan en la baja, densa y asfixiante atmósfera metropolitana. Mi corazón está temblando. Otras veces soy tan alegre como un canario. Saludo a la multitud, silbo con las sirenas, canto con los altavoces: tengo la sensación de viajar con una carga peligrosa, considero estos cuadros como bombas concentradas de explosiones policromadas. Será mi íntima alegría lanzarlos contra los oscuros paralelepípedos de esta Babel. Me siento transportado con ondas altas y bajas de terremoto, me siento rodar con mi obra hacia las profundidades destrozadas de la supermetrópolis, hacia la Gallería Guarino, hacia el “Ring" de mi primera batalla americana» (Depero, 1940: 289).

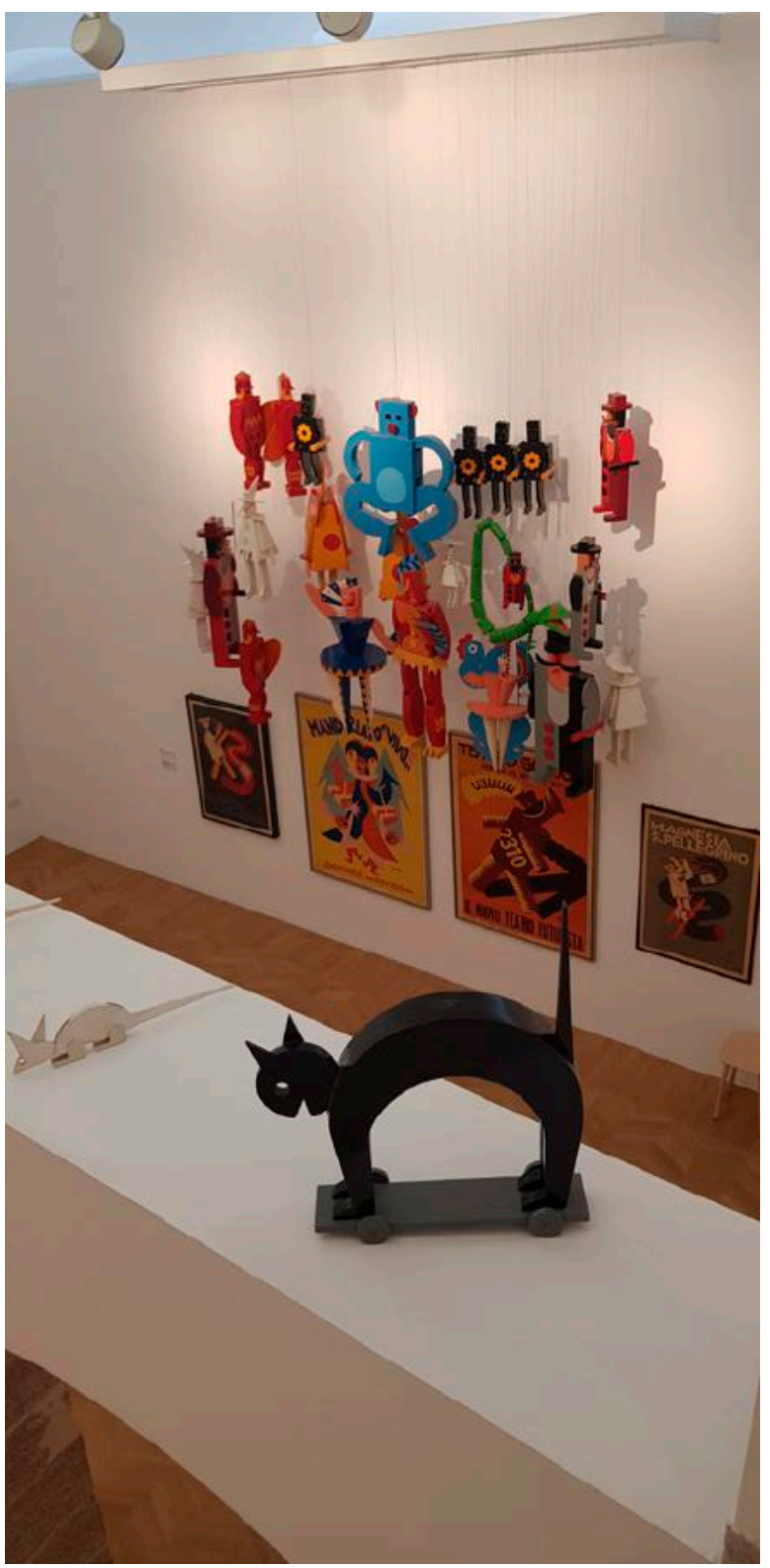

Sala de los tapices. Gatto nero (1918). Al fondo marionetas para los Balli plastici (1918) [Reconstrucción de 1981] En la parte inferior carteles de Mandorlato «Vido» (1924, litografía, 138 x $97 \mathrm{~cm}$ ) y $\mathrm{Il}$ nuovo Teatro Futurista (1924, litografía, 140 x $100 \mathrm{~cm}$ ).

de ventas y el artista tuvo que hacerse cargo de 1200 dólares para poder disolverla. Posteriormente abrió una nueva sede por mediación de la condesa Olga Facchetti Giulia en el 210 de la Quinta Avenida en la Casa del Fascio Femminile «un laboratorio de arte femenino fascista de artes aplicadas modernas» (Belli, 1992: 38). En septiembre de 1929 abandonó el Hotel 
New Transit donde se había alojado y se mudó al estudio de la Quinta Avenida y a un apartamento del 70 West 11th Street.

Pese a que el entorno metropolitano le marcaría de por vida, la renovación de su vocabulario gráfico, el estímulo de la urbe americana y las comisiones que recibió para publicaciones, trabajos de decoración y proyectos teatrales -coincidió con Leónide Massine (1896-1976) al que había conocido en 1916 en París- el sueño de Depero de triunfar en los Estados Unidos fracasaría y le acarrearía una situación financiera calamitosa. El público consideraba demasiado tosco su estilo y el crack bursátil de 1929 agravó aún más su delicada situación económica. Pese a ser uno de los primeros artistas que intuyó el cambio de la capitalidad mundial del arte, las dificultades burocráticas, artísticas y económicas provocaron que su producción se ralentizara.

Cuando Depero volvió a Italia con Rosetta en otoño de 1930, la situación artística y política era muy distinta a la que había dejado y la Casa d'Arte iniciaría un progresivo declive a lo largo de la década convirtiéndose en un laboratorio de artes decorativas ligado al artesanado trentino. Las Case d'Arte habían concluido su ciclo histórico, el futurismo había implementado su política aeropictórica y Depero se terminó distanciando del núcleo romano y de la narrativa de la modernidad ya que la urbe neoyorkina le mostró la cara más desagradable del capitalismo, por lo que se concentraría «en los cánones de la concreción y el realismo» (Scudiero, 1992: 8).

Con escasas opciones de tener encargos públicos y con coleccionistas que ya no estaban interesados en las realizaciones que habían triunfado diez años antes, Depero buscó un nuevo mercado a través de la publicidad como medio hacia el que bascularía el arte contemporáneo como mostró en su «cuadro publicitario no cartel» Squisito al seltz (Óleo/tela, $70 \mathrm{x}$ $100 \mathrm{~cm}$ ) realizado para Campari y expuesto en la Biennale de 1926, que apuntaba a su «Manifesto dell'arte pubblicitaria futurista» publi- cado en el Numero único futurista Campari (1931) y que declaraba que «el arte del futuro será potentemente publicitario» (Depero 1931: 19-21). La política autárquica implementada por el régimen de Mussolini le llevaría a desarrollar trabajos en buxus, material económico a base de celulosa para sustituir el contrachapado de madera a partir de láminas en las que se podían realizar proyectos decorativos de bajo coste. Depero, por otra parte, nunca había escondido sus simpatías por el fascismo y para relanzar su Casa d'Arte pensó en reconvertirla en la denominada Officina d'Arte Fascista. Progetto antisanzionista per lo sviluppo commerciale degli arazzi e cUscini «DEPERO» de abril de 1936 (Dep. 5.25.1) en la que estaba inscrita la propuesta de su Casa-Museo. A partir de las relaciones políticas pudo obtener encargos púbicos y privados en el Trentino, iniciando por otra parte una fructífera colaboración estatal con la ENIT (Agenzia Nazionale del Turismo) que le comisionaría trabajos provinciales y nacionales entre 1938 y 1942.

\section{De la Casa de Arte a la Galeria Museo}

En la última época de Casa d'Arte, Depero pensó en la transformación del taller en un centro monográfico sobre su obra, algo que había planteado en algunos escritos sobre las figuras de Balla y Boccioni (Depero, 1912: 144). En 1941 presentó su «Progetto per una galleria permanente dellopera di Fortunato Depero a Trento» que esperaba realizar cuando terminara la guerra. Depero se trasladaría a Serrada de Folgaria cerrando definitivamente su Casa d'Arte tras entregar su último encargo al Gran Hotel Trento ${ }^{8}$.

La guerra no solo imposibilitó cualquier proyecto, sino que sus afinidades estéticas y políticas lo convirtieron en un personaje in-

\footnotetext{
8 «Debo luchar de tremendamente para pagar los alquileres, los envíos, salvar los secuestros preventivos, pagar las estancias de hotel, saltar las comidas, alimentar a mi mujer y pagar el sábado de cinco a seis operarios que trabajan» (Belli, 1992: 32).
} 
cómodo en la posguerra. Las dificultades económicas en los años últimos del fascismo le llevaron a publicar A passo romano (Trento, 1943) volumen de exaltación patriótica que mantenía destellos del cuidado diseño gráfico que había caracterizado su producción editorial y cuyos remanentes destruyó cuando regresó a Rovereto en 1945.

Durante unos años las relaciones con la comunidad no fueron excesivamente fluidas y para congraciarse con las autoridades permitió al ayuntamiento alojar a personas sin recursos en su casa de Viale dei Colli 38. En 1947, con una situación artística enquistada, fue comisionado parcialmente por la empresa productora del buxus para realizar un segundo viaje a Nueva York con la intención de implementar el material en Norteamérica. Pero los Estados Unidos eran hostiles a los italianos y especialmente a aquellos que hubieran tenido relaciones con el fascismo. Depero, que había viajado solo, ni siquiera pudo alquilar un apartamento y cuando encontró alojamiento solo halló ruidos y molestias. Rosetta llegó posteriormente y fueron invitados por Angela «Lina» Sermolino ( $i$-1948) esposa de William Hillman (1895-1962), relaciones públicas y jefe de prensa de Harry S. Truman a New Milford (Connecticut). En New Milford, Depero encontró un lugar similar a sus orígenes trentinos y pudo desarrollar su trabajo con tranquilidad, una producción por otra parte muy distinta a aquella de la primera estancia, focalizándose en los aborígenes americanos y en una relectura esotérica que caracterizaría su obra de los últimos años y que conformó la mayoría de las imágenes de la exposición permanente de su futuro museo. Los Depero regresaron a Italia en 1949.

La década de los cincuenta supondría la recuperación de su figura. Se publicaron monografías a cargo de los historiadores Giampiero Giani (1912-1964) y Riccardo Maroni (1896-1993) en 1951 y 1953, realizaría una gran muestra individual en Rovereto en 1951 y fue seleccionado en la «Antologia di Maes-

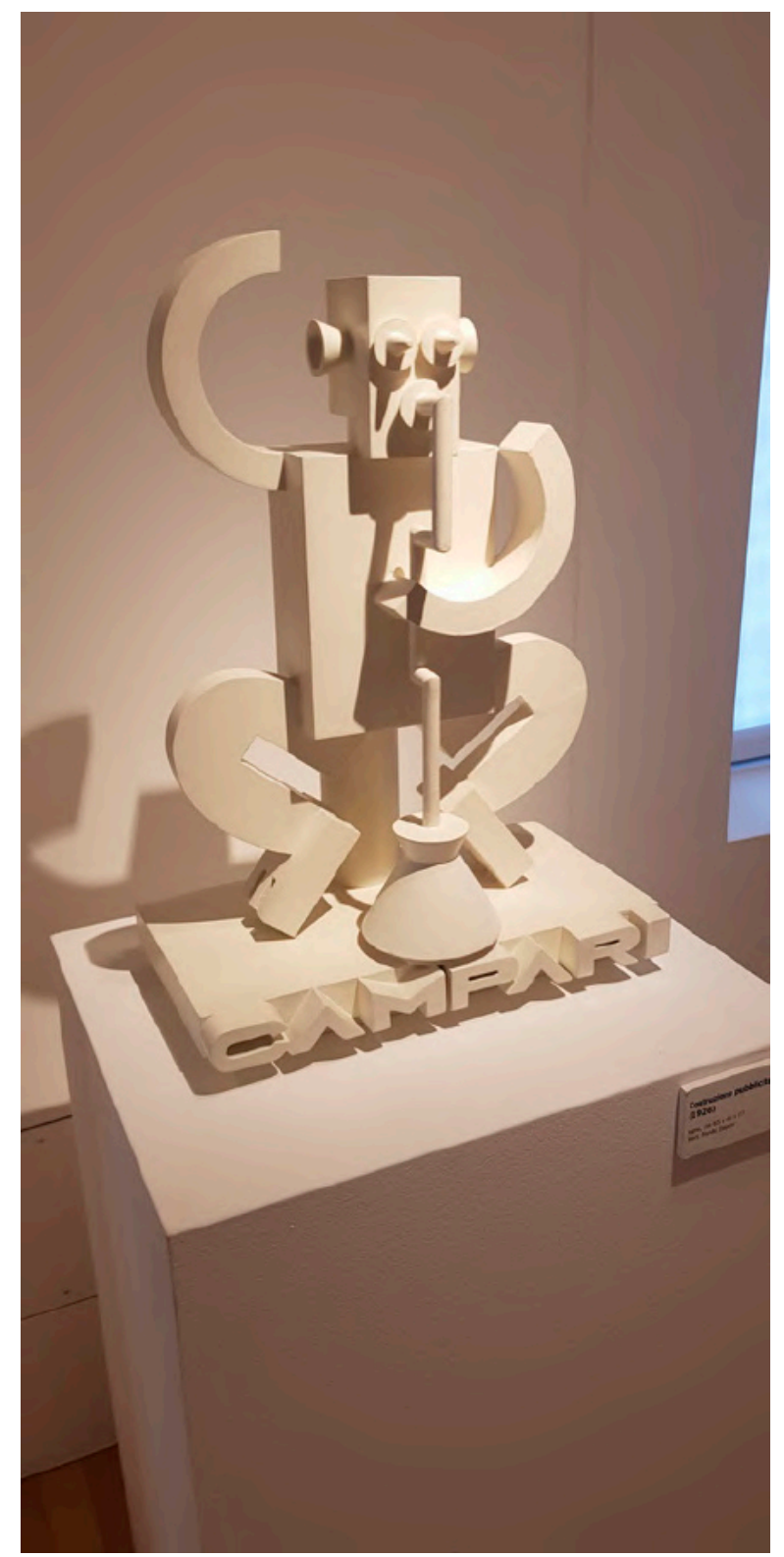

Costruzione pubblicitaria Campari (1926, Madera, 65 x 46 x $27 \mathrm{~cm}$ ).

tri» de la xxvi Biennale de 1952 (Passamani, 1990: 11). El 22 de noviembre de 1952, con motivo de su muestra individual en su casa en viale Dei Colli, Depero escribió al alcalde de Rovereto Giuseppe Veronesi (1910-1985) sobre la creación de un museo permanente sobre su obra dividido en dos partes, una dedicada a su legado y otra para muestras temporales, además de contemplar un taller anexo para los artesanos del Trentino (Boschiero, 2008: 18). 
Este impulso coincidió con el interés suscitado por el encargo del presidente de la provincia de Trento Remo Albertini (1915-2000) para la decoración de la Sala del Consiglio della Provincia Autonoma di Trento (1953-1956) que reconocía su trayectoria y relevancia artística. Depero realizaría una serie de imágenes alegóricas que reconstruían la historia del Trentino diseñándola integralmente, idea que trasladaría posteriormente a su museo. Sin embargo, el reconocimiento no fue igual a nivel nacional. Depero se consideró excluido de la Biennale y publicó el opúsculo de protesta AntiBiennale (1953) en el que incluyó un texto del crítico Lionello Fiumi (1894-1973) que consideraba que la obra de Depero -y el catálogo de que había elaborado- conformaban un museo preliminar.

En septiembre de 1955 el ayuntamiento le comunicó que estudiaría la viabilidad del proyecto de la galería permanente. Depero pensó en un inmueble construido ex profeso y disenó un pabellón para la Galleria pero la falta de espacio en el centro de la ciudad y la carestía de recursos decidieron una intervención en una estructura preexistente. Los técnicos del ayuntamiento pensaron en la casa de Monte dei Pegni, edificio abandonado en el centro del casco histórico y los locales de la ENIT en Piazza Rosmini bajo la logia Vannetti. En 1955 se encargó al arquitecto Mario Kiniger (19141982) -que había realizado la restauración de la fachada de la iglesia de San Marcos en 1950- y al profesor Guido Vettorazzo (19212019) el proyecto eventual para la ubicación del museo para el que eligieron finalmente la casa de Monte dei Pegni.

El inmueble había sido un hospicio anexo a la iglesia de Santa Maria Elisabetta y posteriormente el ayuntamiento había fundado el Monte di Pietà. En enero de 1956 Depero escribió una tercera relación con el título «Galleria permanente e Museo storico Depero» en la que especificaba las salas dedicadas a la ciudad y al "eco della stampa» en las que haría un homenaje a Rovereto y expondría ediciones, volúmenes, catálogos y manifiestos. A modo de soporte técnico para el futuro Museo y en la línea de su frenesí editorial editó dos fascículos del Dizionario volante Depero: voci, significati, aneddoti e opere (Galleria permanente e $\mathrm{Mu}$ seo Storico Depero a Rovereto, 1956 y 1957).

Finalmente se llegó a un acuerdo el 1 de agosto de 1957 para constituir la Galleria permanente y Museo a partir de la cesión de toda su producción artística y su archivo documental. A partir de ese momento y hasta 1959, Depero trabajaría incansablemente en el museo y se trasladó a una nueva vivienda en via Valbusa Grande -en lo que es el actual número 27- para estar más cerca de los trabajos de recuperación del edificio que fueron realizados por empresas a cuenta del artista. Una de sus prioridades fue dotar al inmueble de una estética contemporánea por lo que enmascaró los elementos prexistentes confiriéndole una falsa sensación de actualidad. La experiencia teatral, fundamental en todo su periplo artístico, aparece en la sala Rovereto en la que compuso un escenográfico tríptico de obras relacionadas con el pasado, el presente y futuro de la ciudad: Pietre antiche e moderne (Óleo/ tela, 220 x 168, $5 \mathrm{~cm}$, Mart, 1957), Vampa Eroica (Óleo/tela, 220 x 168,5 cm, Mart, 1957), una síntesis de momentos y espacios ligados a los conflictos bélicos mundiales y Generosità sconfinata (Óleo/tela, 221,5 x $168 \mathrm{~cm}$, Mart, 1957) centrada en Maria Dolens o Campana dei Caduti -haciendo referencia a la vibación del sonido como lo había concebido a partir de sus Liriche radiofoniche- y la heráldica de las ciudades cercanas a Rovereto. Para lograr más recursos, Depero consideró que las empresas de la ciudad se hicieran cargo de una serie de «cuadros publicitarios» en los que vendió a sociedades de la ciudad y de la provincia parte del espacio expositivo que sería decorado por el artista en los que participaron las firmas Molino Costa, Socità Agricoltori Vallagarina, Cofler, Bini Boschetti, Saetta, Nastrificio roveretano, Radi scaldabagni, Cotonificio Rigobello, Komarek y Xilos Ottica Leonardi (Boschiero, 2008: 19) con lo que la publicidad, 


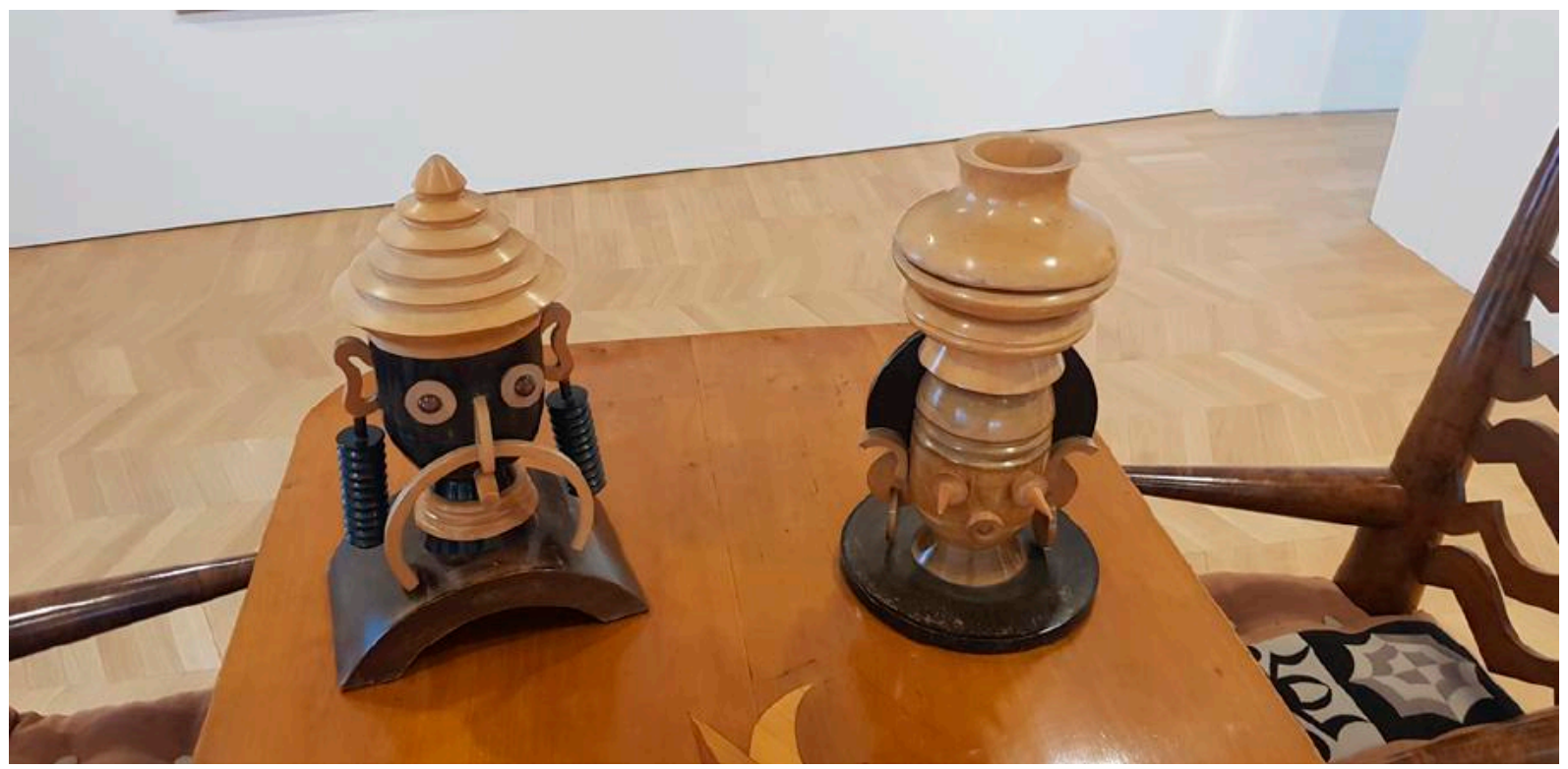

Testa orientale (1930-1934, madera torneada, altura, $44 \mathrm{~cm}$ a.) Teste di cinesi (1930-1934, madera torneada, altura $45 \mathrm{~cm})$.

tal y como había sucedido a lo largo de su carrera, se convertiría en uno de los motivos referenciales del Museo.

El museo se inauguró oficiosamente el 1 de agosto de 1959 anunciándose la apertura más adelante. La salud de Depero, deteriorada desde hacía años, se degradó rápidamente y el artista impuso la modificación del contrato preliminar por el que cedía todo su legado al ayuntamiento el 25 de agosto de 1960 a cambio de una pensión vitalicia para el matrimonio. Depero murió el 29 de noviembre y no pudo ver terminado su Museo. Cuando falleció Rosetta en 1976, el ayuntamiento recuperó las obras en posesión de su viuda y comenzó a gestionar de manera autónoma el patrimonio artístico y documental del pintor.

\section{Del Museo Depero al Mart. Ampliación y restauración de la Casa d'Arte}

Tras su inauguración el museo fue cerrado y sus fondos fueron gestionados por una comisión formada por su viuda, el alcalde de Rovereto y miembros elegidos por el ayuntamiento y por la Accademia Roveretana degli Agiati. La Galeria permaneció cerrada hasta 1975 cuya apertura coincidió con la temporada turística. Entre 1972 y 1978 la Galleria Museo seleccionó un comité de expertos para la catalogación y autentificación de sus obras. En 1974 llegó la donación de los archivos de Angiolo Mazzoni (1894-1979) que, junto a los fondos originales, constituyeron el germen del Archivio del'900. Con una política ligada a la valoración de la vanguardia el ayuntamiento inició la adquisición de obras de Depero y de otros futuristas.

En la década de los ochenta se realizaron una serie de muestras comisariadas por el historiador de arte Bruno Passamani (19302010) que publicó una ambiciosa monografía Fortunato Depero (Comune de Rovereto, 1981) coincidiendo con la nueva revalorización del denominado «segundo futurismo» terminó acuñado por Crispolti en 1958 que se concreta en las grandes muestras del propio Crispolti en Turín (1980) y, en menor medida, de Pontus Hulten en Venecia (1986).

En 1981 la Galleria Museo Depero entró en el organigrama de los Museos Cívicos y en 


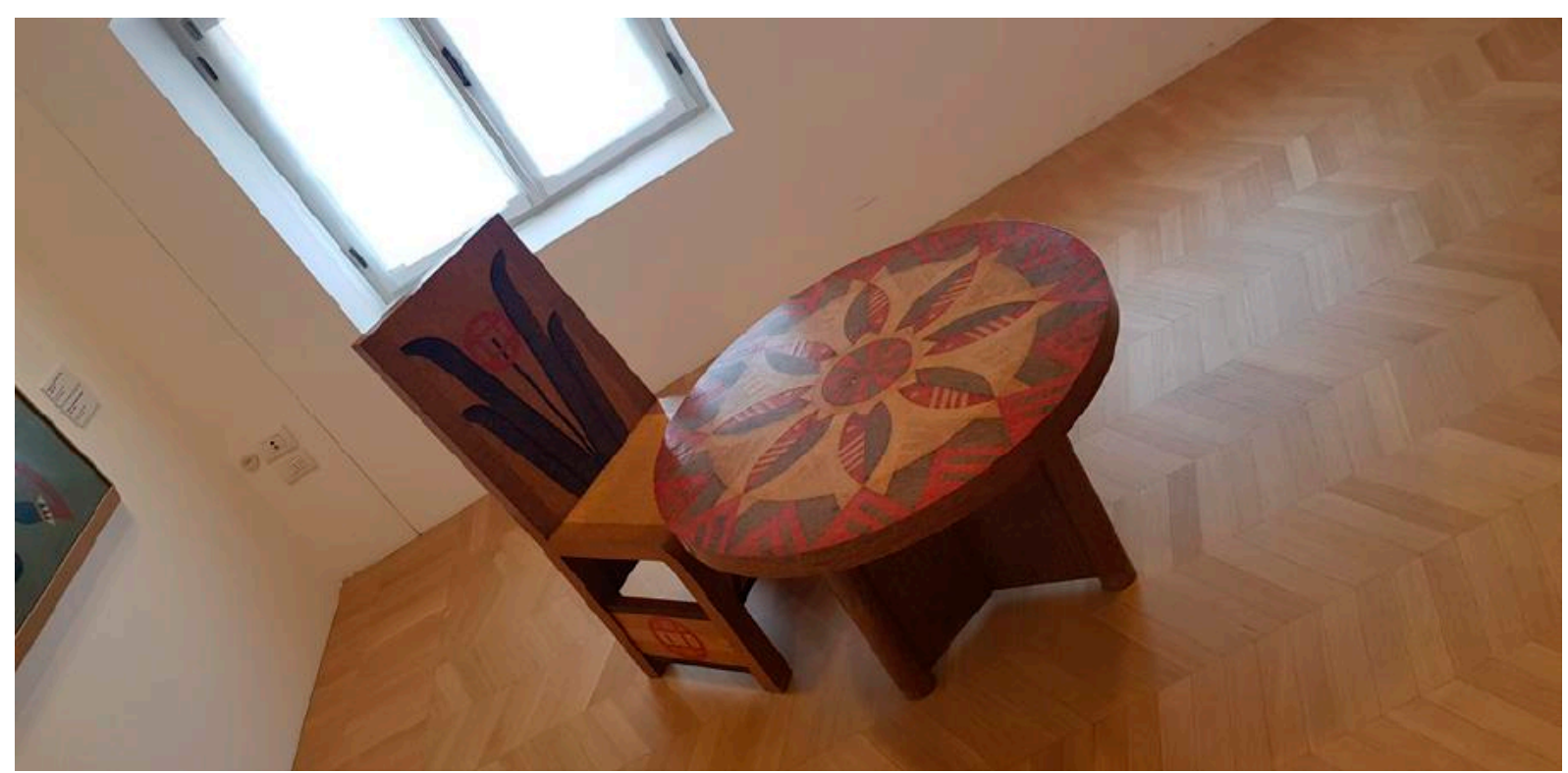

Mobiliario decorado en buxus (mesa: 1938, 64 x $96 \mathrm{~cm}$ diámetro y silla: 1939-1940, buxus, 107 x 59 x $45 \mathrm{~cm}$ )

1986 en la de los museos provinciales, el último paso hasta la institución del Mart un año después. En 1989 los bienes del Ayuntamiento de Rovereto pertenecientes al Galleria Museo Depero fueron puestos a disposición del nuevo ente. De este modo, la Gallería Museo Depero se convirtió en parte de la nueva estructura del Mart que administraría su patrimonio artístico y los documentos que estaban siendo gestionados por el Archivio del'900.

Una de las primeras actuaciones del nuevo ente fue la ampliación del museo. El Mart adquirió Casa Caden y encargó el proyecto al arquitecto y profesor de la IUAV Renato Rizzi (1951-). Rizzi realizó un estudio previo sobre la actuación originaria en el que reconocía la parte del artista, pero no así la del futurismo: «la Galleria nace como voluntad de afirmación, como reconocimiento del propio valor del trabajo» (Rizzi, 1991: 12).

La ampliación vació la Casa Caden para adecuar los nuevos servicios manteniendo intacta la Sala Rovereto que configuraba el núcleo original del museo. Otra de las problemáticas era la exposición adecuada de los tapices cuya dimensión hacía que estuvieran a ras del suelo por lo que el arquitecto propuso una sala de doble altura entre el segundo y el tercer piso.

Rizzi se basó, por otra parte, en la configuración arquitectónica de las pinturas de Depero focalizadas en obras esenciales del artista como Diavoli di caucciù (1919), Corteo della gran bambola (1920), Chiesa di Lizzana (1923), Prismi lunari (1932), Subway, folla ai treni sotterranei (1930) y Apparizioni rusticane (1952). Pese a que Depero realizó algunos proyectos de pabellones publicitarios como el de Bestetti, Tuminelli \& Treves (Belli y Avanzi, 2007: 336-339) para la III Esposizione Internazionale delle Arti Decorative di Monza (1927) y el citado proyecto del museo, Rizzi consideraba que para Depero «la arquitectura no es otra cosa que una cuestión de cartón y tijera» (Rizzi, 1991: 11).

La actuación permitió una nueva entrada por la via Portici y la ampliación de seiscientos metros cuadrados, la mitad de ellos dedicados a espacio expositivo. El proyecto actual se acercaba a la dimensión primigenia concebida por Depero y al programa Ricostruzione futurista dell'universo. La idea era que el espec- 
tador pudiera comprender en toda su magnitud la importancia de la Casa d'Arte a partir de cuadros, diseño de mobiliario, publicidad y ediciones recuperando el espíritu originario del museo.

Coincidiendo con el centenario del movimiento futurista se le encargó a Renato Rizzi la restauración del museo. El arquitecto cimentó su intervención en valores humanísticos que resumió en los siguientes ítems: «La historia: Depero-futurismo; el nombre: arquitectura; lo determinante: estético-estética; Dispositivo: Tecnología-Theologia, imagen: Ausencia presencia» (Rizzi, 2010:13-19).

El proyecto de restauración estuvo fundamentado en la restructuración interna y la reorganización expositiva buscando la creación de un espacio unitario a partir de la relectura del legado histórico del proyecto de Depero. Por tanto, estableció tres tipos de adecuación: las técnico-normativas dedicadas la seguridad del inmueble, las arquitectónico expositivas en las que basaba la restitución del patrimonio y las funcionales, que son las que actualmente rigen la configuración del museo.

\section{La exposición permanente y las muestras temporales}

El proyecto museográfico actual parte de dos espacios concebidos por Fortunato Depero, la Sala Rovereto -en homenaje a la ciudad- y la sala «eco della stampa» que actualmente se estructuran a partir de su formulación original. El acceso al museo lleva a un patio que compondría lo que hubiera sido la cafetería - proyectada por Rizzi pero no realizada- y la entrada al inmueble se distribuye entre la billetería y la tienda que se completa con una instalación compuesta por las botellas en forma de cono que Depero diseñó para Campari en 1932 y que se siguen produciendo como uno de los iconos reconocibles de la marca.

La sala «eco della stampa» presenta un resumen de las ediciones que realizó Depero durante su carrera. Se exponen en unas vitri-

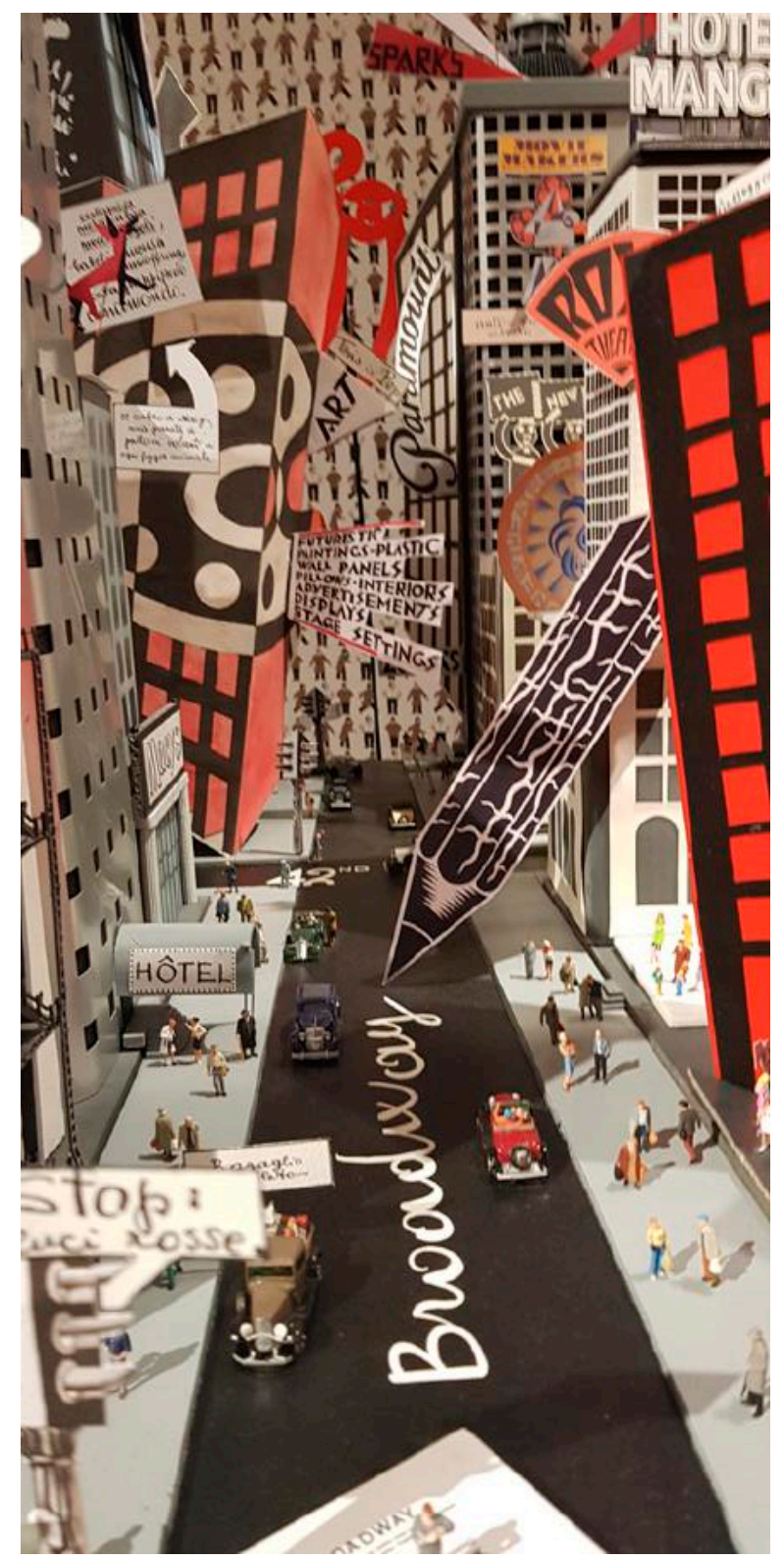

Gaetano Cappa «Drama 1929» (2021) Broadway (Detalle).

nas específicas diseñadas por el artista el libro atornillado Depero Futurista 1913-1927 (Milán, Dinamo Azari, 1927) impreso en Rovereto por la Tipografía Mercurio, al que siguen prácticamente todas las ediciones que realizó: Un istituto per suicidi (Roma, Bernardo Lux Editore, 1917) para Gilbert Clavel; Numero Unico Futurista Campari (Milán, Edizione Davide Campari \& C., 1931); Saggio futurista 1932. Numero unico redatto dal pittore-poeta 
Fortunato Depero in occasione della venuta nel Trentino di S. E. Marinetti (Rovereto, Tipografía Mercurio, 1932); la revista Dinamo futurista (Rovereto, Tipografía Mercurio, 1933); Liriche radiofoniche (Milán, Giuseppe Morreale, 1934); Festa dell'uva. Numero único (Rovereto, Tipografia R. Manfrini, 1936); Fortunato Depero nelle opere e nella vita (Trento, Edizione a cura della Legione Tridentina, 1940); A passo romano. Lirismo fascista e guerriero, programmatico e costruttivo (Trento, Edizioni «Credere - Obbedire - Combattere», 1943) y So I Think. So I Paint. ldeologies of an Italian self-made painter (Milán- Nueva York, 1947) impreso en Trento por la Tipografía editoriale Mutilati e Invalidi. También se exhiben elementos de gráfica publicitaria y los diplomas internacionales que reconocían su obra.

Como se ha señalado, un gran tríptico conforma la sala Rovereto que se completa con cuadros publicitarios en los que Depero resumía y proyectaba la historia de la ciudad. Aparte de un pequeño óleo sobre la iglesia de san Martín de Noriglio, el resto de cuadros que componen la instalación son Diabolicus (Óleo/tela, 1924$1926,125,6 \times 70 \mathrm{~cm}$ ), autorretrato en las montañas del Trentino a partir de una fotografía de las Dolomitas, y tres obras cuyo estilo estaba determinado por el mundo rural y la preferencia esotérica que definió sus últimos años: $\mathrm{Ca}$ valli sulla corda (Óleo/tabla, 95 x $82 \mathrm{~cm}, 1948$ ); Apparizione rusticana (Óleo/tabla, 1952, 201,1 $\mathrm{x} 120 \mathrm{~cm}$ ) y Danza del vento (Óleo/tabla, 1952, $203 \times 120 \mathrm{~cm}$ ) que reseñaba algunos elementos iconográficos de su estancia en New Milford. La sala se completa con muebles y las artes aplicadas como como Pannello con decorazione floreale (Lámina en buxus, 1932, 120 x 293,5 cm).

En el mismo espacio se exponen los bocetos para el Roxy Theater que, junto a gráfica publicitaria de la ciudad norteamericana, componen el espacio dedicado a New York. En Subway (Témpera/papel, 1930, 68 x 102 cm.) y Grattacieli e Tunnel (Témpera/papel, 1930, $68 \times 102 \mathrm{~cm}$ ) transforma la ciudad en una gran máquina dinámica, un engranaje de ruedas, pistones, motores turbinas y todo tipo de elementos mecánicos que configurarían el espacio futurista y que se completan con sus trabajos publicitarios para distintas firmas norteamericanas. Por otra parte, Grattacieli e Tunnel fue utilizada como marco iconográfico de la película Toys (Barry Levinson, 1986).

Entre la segunda y la tercera planta se ubica la sala de los tapices formada por Il corteo della gran bambola (1920) uno de los primeros encargos que recibió la Casa d'Arte por parte del coleccionista Umberto Notari (1878-1950) con motivos de inspiración orientales que remiten a la experiencia de los Balli Plastici y de los ballets rusos; Serrada (1920, Lana sobre algodón, $330 \times 245 \mathrm{~cm}$ ) adquirida en 1925 para una de las salas del Palazzo della Prefettura di Trento; Danza di diavoli (1922, Lana sobre algodón, $180 \times 177 \mathrm{~cm}$ ) una de las escasas piezas que no han desaparecido del romano Cabaret del Diavolo comisionado por Gino Gori (18761952); Lizzana (1923, Lana sobre algodón, 167 $\mathrm{x} 167,5 \mathrm{~cm}$ ) representa la localidad roveretana en una composición influenciada por la estancia en Capri y Festa della sedia (1927, Lana sobre algodón, $330 \times 257 \mathrm{~cm}$.) reconoce algunos elementos diseñados para los diferentes proyectos del pabellón del libro de Monza.

En el mismo espacio están expuestas las reconstrucciones de 1981 de las marionetas de los Balli plastici (1917) que realizó en colaboración con Clavel y que tuvieron una docena de representaciones en el Teatro dei Piccoli en Roma (1918) así como algunos juguetes.

La tercera planta de la Casa d'Arte Futurista Depero se dedica a las muestras temporales, aunque si las exposiciones superan el espacio de la planta se utilizan otras partes del edificio a partir de los paneles diseñados por Depero. Pese a que sea un espacio reducido una de las características de sus exposiciones es que están basadas en la recuperación de la memoria artística del siglo xx. La mayoría de las exhibiciones del Mart parte de un programa propio en el que se le da importancia a los fondos de su colección y al Archivio del'900. En este sentido, la 
Casa d'Arte Depero tiene un programa específicamente ligado con el creador roveretano, con la vanguardia y con toda la poética verbovisual a partir de los años sesenta del pasado siglo.

Es imposible enumerar todas las exposiciones temporales de la Casa d'Arte Futurista Depero pero entre las más destacadas señalar las recientes muestras Drama 1929 y Trilluci de 2021; Il Maestro e Margherita (2018) sobre las relaciones artísticas entre Marinetti y Margherita Sarfatti (1880-1961); Animali metallici. Il culto dellautomobile nel xx secolo (2018) que partía específicamente de los archivos del Mart reconstruyendo el mito de automóvil en la historia visual contemporánea; Performance. Corpo privato e corpo sociale (2016) una lectura del accionismo desde las serate futuristas hasta las prácticas recientes; $\mathrm{LaCi}$ ttà Utopica. Dalla metropoli futurista all'EUR 42 (2016) estructurada sobre la vanguardia arquitectónica, su relación política y la cristalización en el proyecto mussoliniano inconcluso de la Exposición Universal y Tavolara e Depero. La manifattura delle case d'arte (2014) sobre la praxis del artista sardo en relación con la Casa Futurista.

La relectura de la vanguardia y de la obra de Fortunato Depero se ha proyectado en grandes muestras del Mart como La casa del mago. Le arti applicate nell'opera di Fortunato Depero (1993) una ambiciosa propuesta que investigaba la producción y las distintas fases de su Casa d'Arte en el primer edificio del museo situado en el Urban Center de corso Rosmini. En la nueva sede del Mart proyectada por Mario Botta (1943-) y Giulio Andreolli (19512019) se han realizado muestras como La parola nell'arte. Ricerche d'avanguardia nel'900. Dal Futurismo ad oggi attraverso le collezioni del Mart (2007) que partía de los fondos del Mart y del Archivio del'900 para construir una historia de las relaciones palabra imagen del siglo xx; Depero Pubblicitario. Dall'auto-réclame all'architettura pubblicitaria (2007) sobre la relación del artista con el medio publicitario; Futurismo 100. Illuminazioni. Avanguardie a

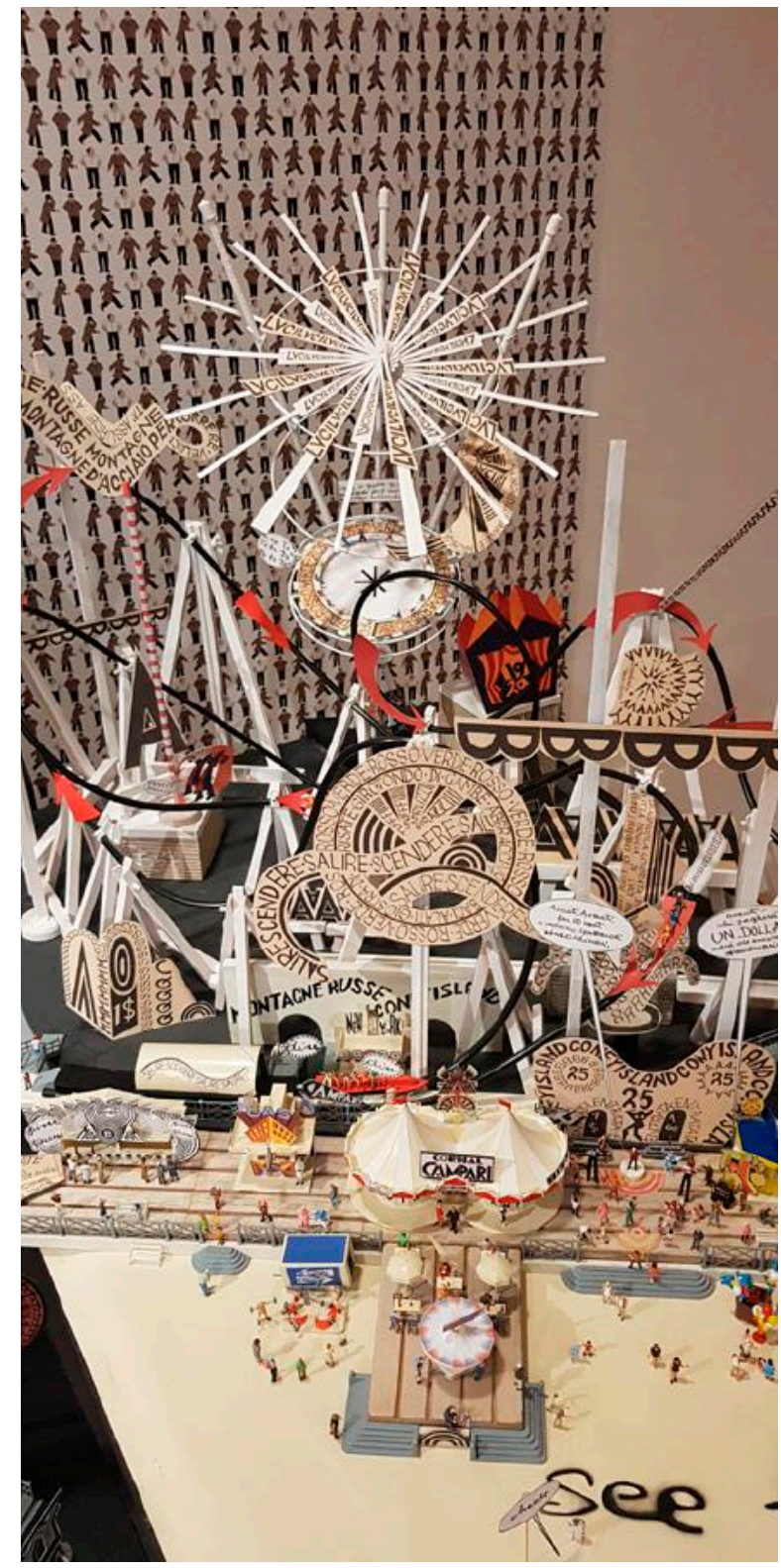

Gaetano Cappa «Drama 1929» (2021) Coney Island (detalle).

confronto: Italia - Germania - Russia (2009) celebrada con motivo del centenario del movimiento futurista o La guerra che verrà non è la prima (1914 - 2014) organizada en el primer centenario de la Primera Guerra Mundial.

\section{Coda}

La historia de la Casa d'Arte Futurista Depero, a la sazón museo de un futurista cuya inten- 
ción era acabar con el pasado y por ende con las instituciones museísticas, hace bueno el dicho italiano, aplicable a todo el movimiento de vanguardia, de que «todos nacemos incendiarios y terminamos siendo bomberos». Toda revolución acaba siendo archivada, asumida por la historia y este, probablemente, represente uno de los mejores ejemplos. De hecho, el camino lo había allanado treinta años antes el propio Marinetti cuando se convirtió en 1931 en Académico de Italia ejemplificando la discordancia de un grupo que había pasado de la abolición del pasado a convertirse en una de las extensiones culturales del régimen político.

En cualquier caso, más allá de simbolizar las contradicciones entre las que los futuristas se movieron sin problema, la Casa d'Arte Futurista Depero se configura como un organismo vivo y dinámico en el organigrama del Mart y del Polo Culturale Museale de Rovereto. Actualmente, la sede de la Casa d'Arte Depero última la gran muestra Depero New Depero programada del 20 de octubre de 2021 al 13 de febrero de 2022 a cargo de Nicoletta Boschiero que estudiará la repercusión de la obra de Depero y sus reminiscencias en el ámbito de las diferentes disciplinas artísticas desde los años sesenta hasta la actualidad. En la Casa d'Arte el historiador Maurizio Scudiero prepara una exposición específica sobre la historia del museo en las mismas fechas. Como preámbulo en la Casa d'Arte se ha podido ver la citada muestra Drama 1929 a cargo de Gaetano Cappa que reconstruye el particular universo propuesto por el artista y que se trasladará igualmente a una novela gráfica que se publicará con motivo de la muestra.

Si el futurismo abogaba por la abolición del pasado denominando a los museos como cementerios, el único museo futurista de Italia tiene una poderosa actividad que refleja los ecos de una vanguardia sorprendente.

\section{BibliografíA}

Bagnoli, Paolo (1992) Futurismo e avanguardie: documenti conservati dalla Fondazione Primo Conti di Fiesole, Trento: Legoprint.

Belli, Gabriella y Beatrice Avanzi (2007) DeperoPubblicitario. Dall'autoréclame all'architettura pubblicitaria. Milán: Skira.

Boschiero, Nicoletta (ed.) (2008) Casa d'Arte futurista Depero, Rovereto: Mart.

Boschiero, Nicoletta (2016) La città utópica. Dalla metrópoli futurista all'EUR 42, Rovereto: Casa d'Arte Futurista Depero.

Boschiero, Nicoletta y Caterina Di Giacomo (2015) La invenzione futurista. Case d'Art di Depero, Presentazione di Enrico Crispolti. Messina: Museo Interdisciplinare Regionale.

Boschiero, Nicoletta (2021) Gaetano Cappa, Depero 1929 Drama. Case d'Arte Futurista Depero.

Boschiero, Nicoletta y Stefano Roffi (2017) Depero il Mago, Milán: Silvana.

Bossaglia, Rossana (1993) Marinetti e il futurismo a Roma: Milán: Fidia/Fonte d'Abisso.

Celant, Germano (2018) Post Zang Tumb Tuuum. Art Life Politics: Italia 1918-1943, Milán: Fondazione Prada.

Cerone, Rocco (2003) Rovereto e il nuovo Polo Museale, Rovereto: Nicolodi.

Collarile, Lucia (1992) Fedele Azari. Vita simultanea futurista, Trento: Museo Aeronautico G. Caproni.

Dalla Chiesa, Giovanna (ed.) (1987) Il museo Primo Conti, Milán: Electa.

DARdi, Domitilla y Bartolomeo Pietromarchi (2021) Casa Balla. Dalla Casa all'universo e ritorno, Venecia: Marsilio.

Dogheria, Duccio (2011) Depero in biblioteca. Libri, riviste e volantini di Fortunato Depero dalle collezioni della Biblioteca Civica "G. Tartarotti", Rovereto: Biblioteca Civica.

Crispolti, Enrico (1980) Ricostruzione futurista del'universo, Turín: Museo Civici.

- (1989) Casa Balla e il futurismo a Roma, Roma: Polgrafico e Zecca dello Stato

Depero, Fortunato (1931) Numero único futurista Campari, Milán: Edizione Davide Campari \& C. 
- (1934) Liriche radiofoniche. Milán: Morreale.

- (1939) Autarchia IRR. Rinnovamente del mobilo e vasto sviluppo dell'instarsio, Trento: Temi.

- (1943) A passo romano. Lirismo fascista e guerriero programmatico e costruttivo, Trento: Edizione di Credere, Obbedire, Combattere.

- (1954) Antibiennale: requisitoria di Fortunato Depero, Rovereto: Manfrini.

- (1959) Galleria Museo Depero Rovereto, Trento: TEMI.

- (2012) Ricostruire e meccanizzare l'universo, Scritti raccolti e curati da Giovani Lista. Milán: Abscondità.

Dogheria, Duccio, et al. (2020) Guida all'Archivio del'900, Rovereto: Mart.

Giacomelli, Milva (2001) «Casa d'Arte» en Godoli, Ezio, (coord.) Il dizionario del futurismo, Florencia: Vallecchi, 232-236.

Giani, Gianpiero (1951) Fortunato Depero, futurista, Milán: Edizioni delle Conchiglia.

Giroud, Vincent y Paola Pettenella (eds.) (2003) Futurism. From Avant-Garde to Memory, Milán: Skira.

Maroni, Ricardo (1977) Fortunato Depero, en Collana Artisti Trentini. Nono Volme. Trento: Arti Grafiche Saturnia, 223-312.

- (1977) Fortunato Depero. Prose futuriste, Trento: Edizione v. D. T. T.

Mondello, Elisabetta (1990) Roma futurista. I periodici e i luoghi dellavanguardia nella Roma degli anni venti, Milán: Franco Angeli.

Passamani, Bruno (ed.) (1970) Fortunato Depero 18921960, Bassano de Grapa: Museo Civico.

— (ed.) (1990) La sala del Consiglio Provinciale di Trento di Fortunato Depero, Trento: Temi.

Rizzi, Renato (ed.) (1991) Galleria Museo Depero. Progetto di ristrutturazione, Roverreto: Manfrini.

Rizzi, Renato, Toffolo, Rafaele y Massimo Donà (2010) Restauro dell Casa d'Arte Futurista Depero, Milán/Udine: Mimesis.

Ruele, Michele (ed.) (1992) Fortunato Depero. Pestavo anchio sul palcoscenico dei ribelli. Antologia degli scritti letterari, Trento: Cucùlibri.

SAlaris, Claudia (1992) Artecrazia. L'avanguardia futurista negli anni del fascismo, Florencia: La Nuova Italia.

SANSONE, Luigi (2009) F. T. MARINETti = Futurismo, Milán: Federico Motta.
Scudiero, Maurizio (1992) Casa d'Arte Futurista Depero, Trento: Il Castello.

Serra, Federico (2021) Marinetti. Retrato de un revolucionario, Madrid: Fórcola.

Scudiero, Maurizio (1988) Depero, Casa d'Arte futuris$t a$, Florencia: Cantini.

Tiddia, Alessandra (ed.) Palazzo delle Albere. Le collezioni del IX secolo del Mart, Guida. Milán: Skira.

Verdone, Mario, Pagnotta, Francesca y Maria BiDETTI, (1992) La Casa d'Arte Bragaglia 1918-1930, Roma: Bulzoni.

Verdú, Daniel (2021) «El futurismo sale del armario», El País, 16 de mayo de 2001, https://elpais.com/ cultura/2021-05-16/el-futurismo-sale-del-armario. html [Fecha de consulta 20/08/2021]

Vv. AA., (1979) Incontro per un museo d'Arte contemporanea a Trento (26 y 27 de junio), Trento: Palazzo delle Albere.

Vv. AA., (1914) Esposizione Libera futurista Intenazionale, Milán: Direzione del Movimento futurista: corso Venezia 61.

Zanoner, Federico (2021) Triluci, Rovereto: Casa d'Arte Futurista Depero.

Recibido el 30 del 8 de 2021

Aceptado el 22 del 9 de 2021

BIBLID [2530-1330 (2021): 130-147] 